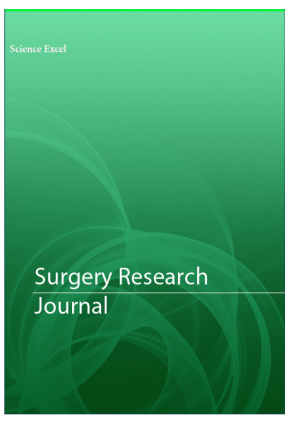

Correspondence

A/Prof Adel Ekladious

Associate Professor of Medicine, Faculty of Health and Medical Sciences, University of Western Australia, G11 M Block. UWA Health Campus (QE11), Monash Avenue, Nedlands 6009, Western Australia

Email: ekladiou@hotmail.com

Mobile: 0499449905

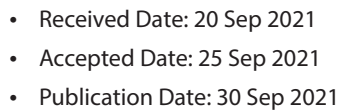

Copyright

(c) 2021 Science Excel. This is an openaccess article distributed under the terms of the Creative Commons Attribution 4.0 International license.

\title{
Rare Cholestatic Form of Stauffer Syndrome
}

\author{
Sharon $\mathrm{XH} \mathrm{Hu}^{1,2}$ and Adel Ekladious ${ }^{3,4}$ \\ 'University of New South Wales (UNSW), Faculty of Medicine, St Vincent's Clinical School, Sydney NSW Australia \\ ${ }^{2}$ Palmerston Regional Hospital, Holtze, NT Australia \\ ${ }^{3}$ University of Western Australia, Faculty of Health \& Medical Sciences, Nedlands WA, Australia \\ ${ }^{4}$ Bega- South East Regional Hospital, SNSWLHD, 4 Virginia Drive, Bega, New South Wales 2550, Australia
}

\begin{abstract}
A 57-year-old man with inexplicable fevers and deranged liver function tests was found to have new renal cell carcinoma on imaging without metastasis. Following surgical resection of the tumour, his fevers immediately disappeared. Stauffer syndrome describes fever associated with renal cell carcinoma and may have accompanying deranged liver biochemistry. Antibiotics should not be automatically prescribed in clinically stable patients who have negative septic and hepatic screens. Instead, a wide differential net should be cast, including for renal cell carcinoma as a potential diagnosis.
\end{abstract}

\section{Introduction}

A 57-year-old man presented to the emergency department with a fever of $39^{\circ} \mathrm{C}$ after a syncopal episode. No tongue biting, incontinence or seizure-like activity were associated with the event. No head injury was sustained. He had no prior coryzal symptoms or cough, abdominal pain, urinary symptoms, altered bowel habits or rash. There were no recent sick contacts or travel history. He also denied experiencing any shortness of breath, chest pain, palpitations, or headache. He did not recall any recent changes to weight or appetite and had not commenced on any new medications.

His past history is significant for ulcerative colitis (medicated with 6-mercaptuopurine \& sulfasalzine), type 2 diabetes (metformin), hypertension, depression, rheumatic fever and nephritis. He lives with his wife and does not partake in smoking, alcohol or recreational drugs.

Vital signs, apart from temperature, were normal on admission. On physical examination, no rash was evident but he displayed scleral icterus. Examination of his neurological, respiratory, cardiovascular and abdominal systems were normal.

Initial laboratory investigations revealed (normal reference range in parentheses): haemoglobin $136 \mathrm{~g} / \mathrm{L}(130-179 \mathrm{~g} / \mathrm{L})$, white cell count $4.97 \times 10^{9} \mathrm{~g} / \mathrm{L} \quad\left(4.0-10.0 \times 10^{9} / \mathrm{L}\right)$, neutrophil $3.42 \times 10^{9} / \mathrm{L} \quad\left(2.0-7.0 \times 10^{9} / \mathrm{L}\right)$, platelets $\quad 149 \times 10^{9} / \mathrm{L} \quad\left(150-400 \times 10^{9} / \mathrm{L}\right)$, erythrocyte sedimentation rate (ESR) $20 \mathrm{~mm} / \mathrm{hr}(0-12 \mathrm{~mm} / \mathrm{hr})$, and C-reactive protein (CRP) $33 \mathrm{mg} / \mathrm{L}(<5 \mathrm{mg} / \mathrm{L})$ which rose to $52 \mathrm{mg} / \mathrm{L}$ on serial testing. Creatinine, urea and electrolytes, as well as calcium magnesium phosphate levels were normal. Cholestatic liver biochemistry was present: total bilirubin $80 \mu \mathrm{mol} / \mathrm{L} \quad(<20 \mu \mathrm{mol} / \mathrm{L})$, gamma glutamyltransferase (GGT) 200U/L (5-50U/L), alkaline phosphatase (ALP) 180U/L (30-110U/L), alanine aminotransferase (ALT) 68U/L (10-50U/L), aspartate transaminase (AST) 50U/L (10$35 \mathrm{U} / \mathrm{L})$ and activated partial prothrombin time (APTT) 39.7sec (25-37sec).

Bedside investigations of urine analysis, electrocardiogram and lumbar puncture tests were unremarkable. Chest x-ray was normal.

He remained clinically stable but was admitted for observation and further workup of his fevers. Serial blood cultures returned no organisms. Chronic hepatitis panel was negative. Q-fever and arbovirus serology testing were similarly negative. Echocardiogram was negative for vegetation.

Despite regular paracetamol, he experienced ongoing temperatures of up to $40^{\circ} \mathrm{C}$. No antibiotic treatment was initiated due to the unclear source of his febrile illness.

Imaging investigation demonstrated hepatosplenomegaly on ultrasound. Computed tomography (CT) of the abdomen revealed a solitary $50 \times 60 \mathrm{~mm}$ lesion in the left kidney with no evidence of liver metastasis (Figure $1 \&$ \& 2 ). These radiologic features favoured the diagnosis of clear cell renal cell carcinoma [1] over von HippelLindau Syndrome which more commonly presents with multiple renal cysts [2], or 


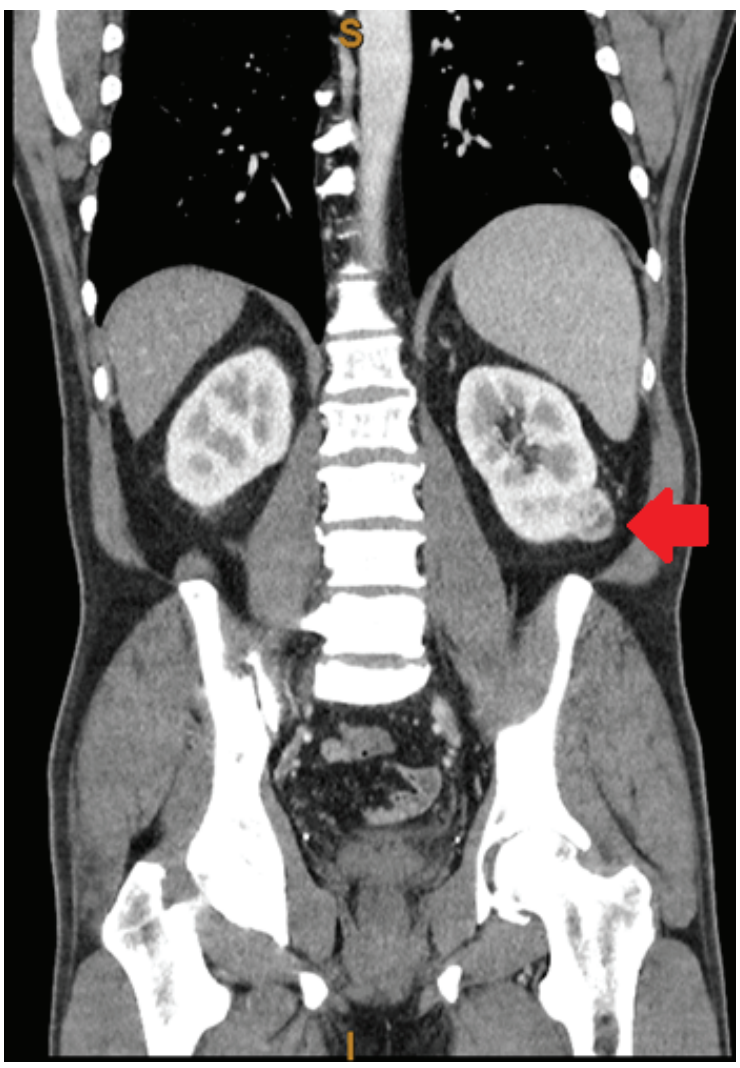

Figure 1.

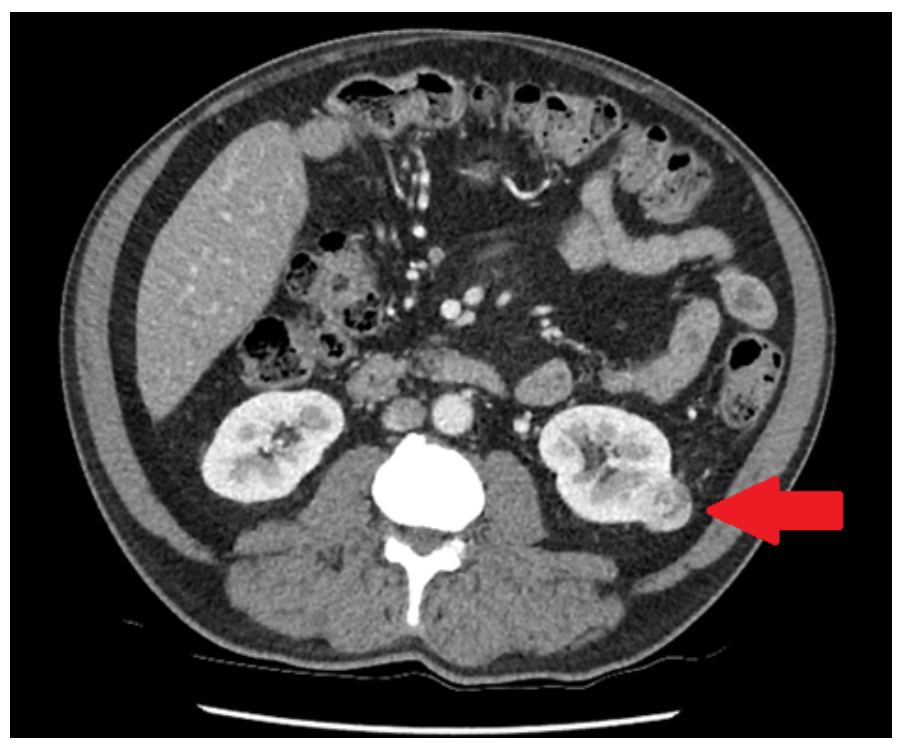

Figure 2.

tuberous sclerosis which typically presents with numerous angiomyolipomas involving both kidneys $[3,4]$.

An urgent urological opinion was sought and laparoscopic resection of the tumour was performed. Surgical histopathology showed an abundance of epithelial cells with clear cytoplasm and highly vascular stroma. Oil red O stain highlighted neutral lipids while periodic-acid Schiff stain identified the presence of glycogen, consistent with clear cell renal cell carcinoma [5].
Following surgery, the patient's recurring fevers promptly resolved. CT pan scan was negative for any metastasis. After a smooth post-operative course where he remained apyrexial, he was discharged home.

\section{Discussion}

Stauffer syndrome is one of the most characteristic paraneoplastic disorders associated with renal cell carcinoma (RCC) [6]. Signs of the syndrome include fever, hepatomegaly, RCC without evidence of metastasis, raised ESR, deranged liver function tests (often a cholestatic picture) and prolonged APTT [7]. Fever may be the sole presenting complaint [8].

The syndrome was first described in 1961 by Herbert Maurice Stauffer and is characterised by elevated ALP and aminotransferases, prolonged APTT, and hepatic dysfunction without liver metastasis [9]. Although Stauffer syndrome is usually associated with RCC, it can also present with other types of malignancies such as prostate cancer, soft-tissue sarcomas, and malignant lymphoproliferative diseases $[10,11]$. More than 100 cases of Stauffer syndrome have since been described in the literature and is commonly divided into non-icteric and, less commonly such as in this case, icteric variants $[12,13]$.

The actual mechanism of the febrile response is unclear. The prevailing theory is that interleukin-6 (IL-6), a proinflammatory cytokine usually secreted by T-cells in the acute phase inflammatory response, plays a role in thermogenesis [14]. RCC may produce an over-expression of IL-6; IL-6 can also elicit an inflammatory response in the liver [15]. Elevated IL- 6 appears to be a recurring theme of Stauffer syndrome with its presence reported in a majority of cases in the literature.

Management of fevers is with operative resection of the RCC. This provides definitive cure with a rapid improvement, if not complete resolution, in symptoms [12]. Immunotherapeutic agents, such as those targeting programmed cell death, programmed death-ligant 1 axis, or novel immune checkpoint inhibitors (such as nivolumab) may be considered in patients with non-clear cells and rare histological subtype RCC [16]. To date, however, a single biomarker as a predictor of response to immunotherapy has not yet been established.

Patients with cholestatic hepatitis and fever should be investigated for RCC if septic screen is negative and should not be treated with antibiotics if they are well compensated. Instead, treatment via surgery or immune checkpoint inhibitor should be offered, dependent on the histology of the renal mass.

\section{Acknowledgements}

No financial grants or funding were received for this article.

\section{Authors Details \& Contributions}

\section{Dr Sharon XH Hu}

- Resident Medical Officer at Palmerston Regional Hospital, NT, Australia

- Associate Lecturer at UNSW St Vincent's Clinical School, NSW, Australia 
- $\quad 90 \%$ : case write-up

\section{A/Prof Adel Ekladious}

- Consultant General Physician at Bega District Hospital, Bega NSW Australia

- Associate Professor at University of Western Australia, WA

- 10\%: proof-reading \& clinical case management

\section{References}

1. Northrup BE, Jokerst CE, Grubb RL 3rd, Menias CO, Khanna $\mathrm{G}$, Siegel CL. Hereditary renal tumor syndromes: imaging findings and management strategies. AJR Am J Roentgenol. 2012;199(6):1294-1304.

2. Choyke PL, Glenn GM, Walther MM, Patronas NJ, Linehan WM, Zbar B. von Hippel-Lindau disease: genetic, clinical, and imaging features. Radiology. 1995;194(3):629-642.

3. Choyke PL, Glenn GM, Walther MM, Zbar B, Linehan WM. Hereditary renal cancers. Radiology. 2003;226(1):33-46.

4. Casper KA, Donnelly LF, Chen B, Bissler JJ. Tuberous sclerosis complex: renal imaging findings. Radiology. 2002;225(2):451456.

5. Kar A, Pattnaik K, Kar T, Biswal P, Mishra C, Guru L. Clear cell lesions in pathology: Histomorphologic approach to diagnosis. Indian J Pathol Microbiol. 2020;63(2):177-187.

6. Chavarriaga J, Fakih N, Catano J, Villaquiran C, Rodriguez $\mathrm{S}$, Patino G. Stauffer syndrome, clinical implications and knowledge gaps, does size matter? Case report. BMC Urol. 2020;20(1):105.

7. Dourakis SP, Sinani C, Deutsch M, Dimitriadou E, Hadziyannis
SJ. Cholestatic jaundice as a paraneoplastic manifestation of renal cell carcinoma. Eur J Gastroenterol Hepatol. 1997;9(3):3114.

8. Gold PJ, Fefer A, Thompson JA. Paraneoplastic manifestations of renal cell carcinoma. Semin Urol Oncol. 1996;14(4):216-22.

9. Stauffer M. Nephrogenic hepatomegaly. Gastroenterology. 1961(40):694.

10. Fontes-Sousa M, Magalhaes H, da Silva FC, Mauricio MJ. Stauffer's syndrome: A comprehensive review and proposed updated diagnostic criteria. Urol Oncol. 2018;36(7):321-6.

11. Sharma N, Darr U, Darr A, Sood G. Stauffer Syndrome: A Comprehensive Review of the Icteric Variant of the Syndrome. Cureus. 2019;11(10):e6032.

12. Puga M, Gonzalez-Ballina E, Rivas-Moral L. Stauffer's Syndrome Variant as an Unusual Case of Painless Jaundice. Clin Gastroenterol Hepatol. 2015;13(9):A25-6.

13. Morla D, Alazemi S, Lichtstein D. Stauffer's syndrome variant with cholestatic jaundice: a case report. J Gen Intern Med. 2006;21(7):C11-3.

14. Karakolios A, Kasapis C, Kallinikidis T, Kalpidis P, Grigoriadis $\mathrm{N}$. Cholestatic jaundice as a paraneoplastic manifestation of prostate adenocarcinoma. Clin Gastroenterol Hepatol. 2003;1(6):480-3.

15. Blay JY, Rossi JF, Wijdenes J, et al. Role of interleukin- 6 in the paraneoplastic inflammatory syndrome associated with renalcell carcinoma. Int J Cancer. 1997;72(3):424-30.

16. Lavacchi D, Pellegrini E, Palmieri VE, et al. Immune Checkpoint Inhibitors in the Treatment of Renal Cancer: Current State and Future Perspective. Int J Mol Sci. 2020;21(13). 